\title{
Tamanho de amostra para a estimação da média de caracteres de pêssego na colheita e após 0 armazenamento refrigerado
}

\author{
Sample size to estimate the average peach characters at harvest and after cold storage
}

\author{
Marcos Toebe $^{{ }^{*}}$ Vanderlei Both $^{\mathrm{I}}$ Auri Brackmann ${ }^{\mathrm{II}}$ Alberto Cargnelutti Filho ${ }^{\mathrm{II}}$ \\ Fabio Rodrigo Thewes ${ }^{\text {III }}$
}

\begin{abstract}
O objetivo deste trabalho foi determinar o tamanho de amostra necessário para avaliar caracteres de frutos de pêssego na colheita e após o armazenamento refrigerado. Foram colhidos frutos de um pomar comercial. No laboratório, separaram-se, aleatoriamente, duas amostras de 120 frutos de pêssego, sendo uma amostra avaliada na colheita e a outra armazenada a $-0,5^{\circ} \mathrm{C}$ por 30 dias, mais cinco dias a $20^{\circ} \mathrm{C}$. Foram mensurados 11 caracteres em cada fruto na colheita $e$ 12 caracteres após o armazenamento refrigerado, sendo calculadas medidas de tendência central e de dispersão $e$ verificada a normalidade. Posteriormente, compararam-se as médias e verificou-se a homogeneidade de variâncias dos caracteres avaliados na colheita e após o armazenamento refrigerado. A seguir, foi determinado o tamanho de amostra para cada caractere. São necessários 169 frutos para estimar a firmeza de polpa, 34 frutos para estimar a massa, a acidez $e$ o ratio, 11 frutos para avaliar a suculência e seis frutos para estimar os demais caracteres na colheita e após o armazenamento refrigerado, com erro de estimação de 5\% da média.
\end{abstract}

Palavras-chave: Prunus persica, dimensionamento de amostra, planejamento experimental.

\section{ABSTRACT}

The aim of this research was to determine the sample size needed to evaluate peach fruit characters at harvest and after cold storage. Fruits were collected from a commercial orchard. In the laboratory, split randomly, two samples of 120 fruits each, one sample assessed at harvest and one stored at $-0.5^{\circ} \mathrm{C}$ for 30 days, and then for five additional days at $20^{\circ} \mathrm{C}$. Eleven characters were measured on each fruit at harvest and twelve after cold storage, being the central tendency measures and dispersion calculated and normality checked. After, it was compared the average and the homogeneity of variance at harvest and after cold storage and calculated the sample size for each character. In peach, 169 fruits are needed to estimate the pulp firmness, 34 fruits to estimate the weight, acidity and ratio, 11 fruits to assess fruit juiciness and six fruits to estimate the others characters at harvest and after cold storage, with an estimation error of $5 \%$ on average.

Key words: Prunus persica, sample dimensioning, experimental planning.

O cultivo de frutas de caroço (Prunus ssp.) possui importância econômica e social nos estados da região sul e sudeste do Brasil, principalmente no Estado do Rio Grande do Sul, responsável por mais de $60 \%$ da produção nacional (BARBOSA et al., 2010; OLIVEIRA et al., 2011). Devido ao curto período de colheita e à alta pericibilidade, é necessário que os frutos sejam armazenados adequadamente para aumentar o período de oferta ao consumidor (CERETTA et al., 2000; BARBOSA et al., 2010). A fim de avaliar a qualidade dos frutos, são mensurados seus caracteres químicos e físicos em pós-colheita (ARAÚJO et al., 2008).

A qualidade da análise dos dados experimentais depende do correto dimensionamento da amostra. O tamanho de amostra é diretamente proporcional à variabilidade dos dados e à

IPrograma de Pós-graduação em Agronomia, Universidade Federal de Santa Maria (UFSM), 97105-900, Santa Maria, RS, Brasil. Email: m.toebe@gmail.com.*Autor para correspondência.

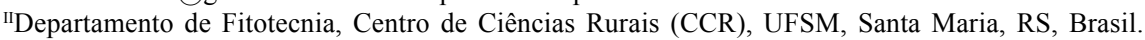

IIICurso de Agronomia, UFSM, Santa Maria, RS, Brasil. 
confiabilidade desejada na estimativa e inversamente proporcional ao erro de estimação permitido a priori pelo pesquisador (SPIEGEL et al., 2004). Contudo, trabalhos que determinem o tamanho de amostra necessário para avaliar caracteres de pêssego em póscolheita não foram encontrados na literatura. Assim, o objetivo deste trabalho foi determinar o tamanho de amostra necessário para avaliar caracteres de frutos de pêssego na colheita e após o armazenamento refrigerado.

Os pêssegos da cultivar 'Eldorado' foram colhidos no dia 28/12/2010, em um pomar comercial de oito anos de idade, localizado no município de Santiago, Estado do Rio Grande do Sul. Após a colheita, os frutos foram separados, aleatoriamente, em duas amostras de 120 cada, no Núcleo de Pesquisa em Pós-Colheita do Departamento de Fitotecnia da Universidade Federal de Santa Maria. Uma amostra foi avaliada no dia da colheita e outra foi armazenada à temperatura de $-0,5^{\circ} \mathrm{C}$ por 30 dias, mais cinco dias à $20^{\circ} \mathrm{C}$. Em cada fruto, de cada amostra, foram mensurados os seguintes caracteres: massa, comprimento, diâmetros maior e menor, com o auxílio de uma balança e de um paquímetro; luminosidade (L), intensidade (C) e tonalidade de cor $\left(\mathrm{h}^{\mathrm{o}}\right)$, determinados com um colorímetro eletrônico da marca Minolta, modelo CR310 que utiliza o sistema tridimensional de cores CIELAB; firmeza de polpa, com um penetrômetro manual com ponteira de $7,9 \mathrm{~mm}$, inserido em dois lados opostos da região equatorial de cada fruto; sólidos solúveis totais (SST), com o uso de um refratômetro e expresso em ${ }^{\circ}$ Brix; acidez, determinada por titulometria, expressa em percentagem de ácido cítrico; ratio, que é a relação entre os SST e acidez. A suculência de cada um dos 120 frutos foi mensurada apenas após o armazenamento refrigerado, com o auxílio de uma prensa pneumática que, por meio de um pistão, prensou uma amostra de aproximadamente 20 gramas da polpa de cada fruto, colocada entre duas tiras de esponjas contra uma massa de $1.500 \mathrm{~kg}$. Após 30 segundos de prensagem, pesouse a parte da polpa que ficou entre as duas esponjas e, por diferença com a amostra inicial, obteve-se a quantidade de suco extraído de cada fruto.

Para cada caractere de cada amostra, foram calculadas medidas de tendência central, de variabilidade, de assimetria e de curtose e verificada a normalidade por meio do teste de KolmogorovSmirnov. Aplicaram-se os testes t (bilateral) e F (bilateral), a 5\% de probabilidade de erro, para testar, respectivamente, as hipóteses de igualdade entre as médias e de homogeneidade entre as variâncias de cada um dos 11 caracteres mensurados na colheita e após o armazenamento refrigerado.
Com base nos 120 frutos de cada amostra, calculou-se o tamanho de amostra $(\eta)$ para as semiamplitudes do intervalo de confiança (erro de estimação) iguais a $1,2, \ldots, 10 \%$ da estimativa da média (m), com grau de confiança (1- $\alpha$ ) de $95 \%$, por meio da expressão $\eta=\frac{t_{\alpha / 2}^{2} s^{2}}{(\text { erro de estimação })^{2}}$ (SPIEGEL et al., 2004), em que, $t_{\alpha / 2}$ é o valor crítico da distribuição t de Student, cuja área à direita é igual a $\alpha / 2$, com (n-1) graus de liberdade, com $\alpha=5 \%$ de probabilidade de erro, e s é a estimativa de variância. Posteriormente, fixou-se

em 120 frutos e foi calculado o erro de estimação em percentagem da estimativa da média $(\mathrm{m})$ para cada caractere, por meio da expressão erro de estimação = $100 \frac{\mathrm{t}_{\alpha / 2} \mathrm{~s}}{\sqrt{\eta} \mathrm{m}}$, em que s é a estimativa do desvio padrão. As análises estatísticas foram realizadas com o programa GENES (CRUZ, 2006) e o Office Excel.

A massa e os diâmetros maior e menor de frutos, mensurados na colheita, não se alteraram $(\mathrm{P}>0,05)$ após o armazenamento refrigerado. Já o comprimento apresentou uma leve superioridade $(\mathrm{P}=0,0188)$ na colheita (Tabela 1$)$. Todos os demais caracteres modificaram-se em função do armazenamento refrigerado. Os valores médios de luminosidade e de intensidade de cor aumentaram, enquanto a tonalidade de cor e a firmeza de polpa diminuíram, o que indica processo de maturação de frutos. A concentração de sólidos solúveis totais e a acidez dos frutos reduziram após o armazenamento refrigerado, sendo que a redução mais expressiva da acidez propiciou aumento do ratio. A suculência média dos frutos de pêssego após o armazenamento foi de $66,05 \%$.

As variâncias entre as duas mensurações (na colheita e após o armazenamento) dentro dos caracteres massa, comprimento, diâmetros maior e menor e luminosidade foram homogêneas (Tabela 1). Para os demais caracteres, as variâncias foram heterogêneas e, nesse caso, deve-se calcular um tamanho de amostra específico para as mensurações na colheita e após o armazenamento refrigerado.

A firmeza de polpa apresentou maior coeficiente de variação ( $C V=22,32 \%$ e $C V=32,78 \%$ ), na colheita e após o armazenamento refrigerado, respectivamente, e os caracteres massa, acidez e ratio apresentaram variabilidade intermediária $(12,16 \% \leq \mathrm{CV} \leq 14,71 \%)$. Já, os demais caracteres apresentaram menor variabilidade $(\mathrm{CV} \leq 8,33 \%)$ (Tabela 1). Esses resultados sugerem maiores tamanhos de amostra para a estimação da média da firmeza de polpa, seguidos da massa, ratio e acidez, em relação aos demais caracteres. 
Tabela 1 - Mínimo, máximo, média, variância (Var), coeficiente de variação (CV\%), assimetria (AS), curtose + 3 (CT) e p-valor do teste de normalidade de Kolmogorov-Smirnov para 11 caracteres mensurados na colheita e 12 caracteres mensurados após o armazenamento refrigerado de amostras de 120 frutos de pêssego.

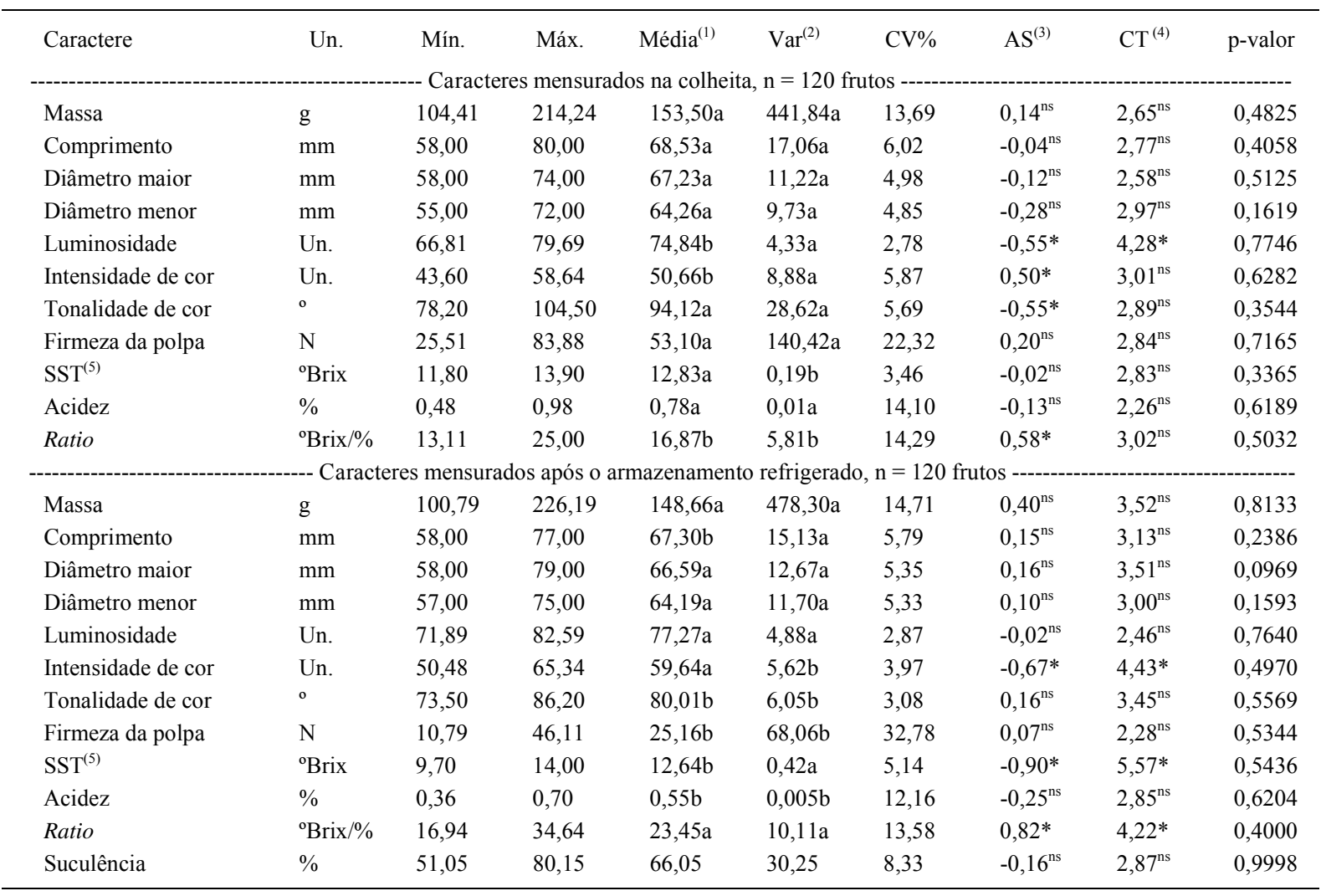

(1) As médias dos caracteres mensurados na colheita e após o armazenamento refrigerado não seguidas pela mesma letra diferem pelo teste t bilateral, a 5\% de probabilidade de erro.

(2) As variâncias dos caracteres mensurados na colheita e após o armazenamento refrigerado não seguidas pela mesma letra são heterogêneas pelo teste $\mathrm{F}$ bilateral, a $5 \%$ de probabilidade de erro.

(3)* Assimetria difere de zero, pelo teste $\mathrm{t}$, em nível de $5 \%$ de probabilidade. ${ }^{\mathrm{ns}}=$ Não-significativo.

(4)* Curtose difere de três, pelo teste $\mathrm{t}$, em nível de $5 \%$ de probabilidade. ${ }^{\text {ns }}=$ Não-significativo.

(5) Sólidos solúveis totais.

Em relação aos 23 casos (11 caracteres mensurados na colheita e 12 após o armazenamento), $69,6 \%$ (16 casos) apresentaram assimetria não diferente de zero, 82,6\% (19 casos) apresentaram curtose não diferente de três e em todos os casos os dados se ajustaram à distribuição normal ( $\mathrm{P}$ 0,0969) (Tabela 1). Assim, pode-se inferir que os dados são adequados para a estimativa do tamanho de amostra pela distribuição t de Student.

O tamanho de amostra para a estimação da média, com erro de estimação igual a $1 \%$ da média, variou de 31 a 1.954 frutos e de 33 a 4.213 frutos, na colheita e após o armazenamento refrigerado, respectivamente, para os caracteres luminosidade $\mathrm{e}$ firmeza de polpa (Tabela 2). Considerando um erro de estimação igual a 5\% da média, o tamanho de amostra oscilou entre 2 e 79 e entre 2 e 169 frutos, para os mesmos caracteres, respectivamente, na colheita e após o armazenamento refrigerado. Essa ampla variabilidade já foi verificada em estudos de tamanho de amostra para outras culturas, como em crambe, em que para um erro de estimação igual a $1 \%$ da média, para diferentes caracteres, é necessário avaliar de 1.516 a 15.241 plantas (CARGNELUTTI FILHO et al., 2010b) e, em caracteres de híbridos de mamona, em que se necessita avaliar de 18 a 6.077 plantas, com erro de estimação de $2 \%$ da média (CARGNELUTTI FILHO et al., 2010a).

Em pêssego, são necessários 169 frutos para estimar a firmeza de polpa, 34 frutos para estimar a massa, a acidez e o ratio, 11 frutos para estimar a suculência e seis frutos para estimar os demais caracteres na colheita e após o armazenamento refrigerado com erro de estimação de $5 \%$ da média. 
Tabela 2 - Tamanho de amostra (número de frutos) para a estimação da média de 11 caracteres mensurados na colheita e 12 caracteres mensurados após o armazenamento refrigerado de frutos de pêssego, para os erros de estimação iguais a $1,2, \ldots, 10 \%$ da estimativa da média, e a semiamplitude do intervalo de confiança (Erro\%), com base nos 120 frutos avaliados.

\begin{tabular}{|c|c|c|c|c|c|c|c|c|c|c|c|}
\hline Caractere & $1 \%$ & $2 \%$ & $3 \%$ & $4 \%$ & $5 \%$ & $6 \%$ & $7 \%$ & $8 \%$ & $9 \%$ & $10 \%$ & $\begin{array}{c}\text { Erro } \\
(\%)\end{array}$ \\
\hline \multicolumn{12}{|c|}{ 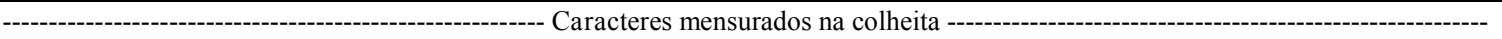 } \\
\hline Massa & 736 & 184 & 82 & 46 & 30 & 21 & 16 & 12 & 10 & 8 & 2,47 \\
\hline Comprimento & 143 & 36 & 16 & 9 & 6 & 4 & 3 & 3 & 2 & 2 & 1,09 \\
\hline Diâmetro maior & 98 & 25 & 11 & 7 & 4 & 3 & 2 & 2 & 2 & 1 & 0,90 \\
\hline Diâmetro menor & 93 & 24 & 11 & 6 & 4 & 3 & 2 & 2 & 2 & 1 & 0,88 \\
\hline Luminosidade & 31 & 8 & 4 & 2 & 2 & 1 & 1 & 1 & 1 & 1 & 0,50 \\
\hline Intensidade de cor & 136 & 34 & 16 & 9 & 6 & 4 & 3 & 3 & 2 & 2 & 1,06 \\
\hline Tonalidade de cor & 127 & 32 & 15 & 8 & 6 & 4 & 3 & 2 & 2 & 2 & 1,03 \\
\hline Firmeza da polpa & 1.954 & 489 & 218 & 123 & 79 & 55 & 40 & 31 & 25 & 20 & 4,03 \\
\hline $\mathrm{SST}^{(1)}$ & 47 & 12 & 6 & 3 & 2 & 2 & 1 & 1 & 1 & 1 & 0,63 \\
\hline Acidez & 780 & 195 & 87 & 49 & 32 & 22 & 16 & 13 & 10 & 8 & 2,55 \\
\hline Ratio & 801 & 201 & 89 & 51 & 33 & 23 & 17 & 13 & 10 & 9 & 2,58 \\
\hline \multicolumn{12}{|c|}{--- Caracteres mensurados após o armazenamento refrigerado --- } \\
\hline Massa & 849 & 213 & 95 & 54 & 34 & 24 & 18 & 14 & 11 & 9 & 2,66 \\
\hline Comprimento & 132 & 33 & 15 & 9 & 6 & 4 & 3 & 3 & 2 & 2 & 1,05 \\
\hline Diâmetro maior & 113 & 29 & 13 & 8 & 5 & 4 & 3 & 2 & 2 & 2 & 0,97 \\
\hline Diâmetro menor & 112 & 28 & 13 & 7 & 5 & 4 & 3 & 2 & 2 & 2 & 0,97 \\
\hline Luminosidade & 33 & 9 & 4 & 3 & 2 & 1 & 1 & 1 & 1 & 1 & 0,52 \\
\hline Intensidade de cor & 62 & 16 & 7 & 4 & 3 & 2 & 2 & 1 & 1 & 1 & 0,72 \\
\hline Tonalidade de cor & 38 & 10 & 5 & 3 & 2 & 2 & 1 & 1 & 1 & 1 & 0,56 \\
\hline Firmeza da polpa & 4.213 & 1.054 & 469 & 264 & 169 & 118 & 86 & 66 & 53 & 43 & 5,93 \\
\hline $\mathrm{SST}^{(1)}$ & 104 & 26 & 12 & 7 & 5 & 3 & 3 & 2 & 2 & 2 & 0,93 \\
\hline Acidez & 580 & 145 & 65 & 37 & 24 & 17 & 12 & 10 & 8 & 6 & 2,20 \\
\hline Ratio & 723 & 181 & 81 & 46 & 29 & 21 & 15 & 12 & 9 & 8 & 2,46 \\
\hline Suculência & 272 & 68 & 31 & 17 & 11 & 8 & 6 & 5 & 4 & 3 & 1,51 \\
\hline
\end{tabular}

(1) Sólidos solúveis totais.

\section{REFERÊNCIAS}

ARAÚJO, J.P.C. et al. Influência da poda de renovação e controle da ferrugem nas reservas de carboidratos e produção de pessegueiro precoce. Revista Brasileira de Fruticultura, v.30, p.331-335, 2008. Disponível em: <http://www.scielo.br/ pdf/rbf/v30n2/a11v30n2.pdf>. Acesso em: 13 out. 2011. doi: dx.doi.org/10.1590/S0100-29452008000200011.

BARBOSA, W. et al. Advances in low-chilling peach breeding at Instituto Agronômico, São Paulo State, Brazil. Acta Horticulturae, v.872, p.147-150, 2010. Disponível em: $<$ http://www.actahort.org/books/872/872_17.htm>. Acesso em: 27 out. 2011.

CARGNELUTTI FILHO, A. et al. Tamanho de amostra de caracteres em híbridos de mamoneira. Ciência Rural, v.40, p.250-257, 2010a. Disponível em: <http://www.scielo.br/pdf/ cr/v40n2/a469cr2481.pdf >. Acesso em: 03 mar. 2010. doi: 10.1590/S0103-84782010000200005.

CARGNELUTTI FILHO, A. et al. Tamanho de amostra e relações lineares de caracteres morfológicos e produtivos de crambe.
Ciência Rural, v.40, p. 2262-2267, 2010b. Disponível em: $<$ http://www.scielo.br/pdf/cr/v40n11/a774cr3308.pdf $>$. Acesso em: 03 mar. 2010. doi: 10.1590/S0103-84782010001100003.

CERETTA, M. et al. Conservação em atmosfera controlada de pêssego cultivar Eldorado. Ciência Rural, v.30, p.73-79, 2000. Disponível em: <http://www.scielo.br/pdf/cr/v30n1/ a12v30n1.pdf $>$. Acesso em: 03 mar. 2011. doi: 10.1590/ S0103-84782000000100012.

CRUZ, C.D. Programa genes: estatística experimental e matrizes. Viçosa: UFV, 2006. 285p.

OLIVEIRA, M.C. et al. Seleção de ameixeiras promissoras para a Serra da Mantiqueira. Revista Ceres, v.58, p.531-535, 2011. Disponível em: <http://www.scielo.br/pdf/rceres/v58n4/ a19v58n4.pdf $>$. Acesso em: 11 mar. 2011. doi: dx.doi.org/ 10.1590/S0034-737X2011000400019.

SPIEGEL, R.A. et al. Probabilidade e estatística. 2.ed. Porto Alegre: Bookman, 2004. 398p. 